\title{
ANÁLISE DA SITUAÇÃO FINANCEIRA DO ESTADO DO TOCANTINS POR CATEGORIA ECONÔMICA
}

\author{
Analysis Of The Financial Situation Of The State Of Tocantins By Economic Category \\ Análisis De La Situación Financiera Del Estado De Tocantinas Por Categoría \\ Económica
}

\section{Reinaldo Pereira de Brito Costa ${ }^{1}$, Nilton Marques de Oliveira ${ }^{2}$, Fernando Silva Lima*3}

${ }^{1}$ Mestrado em Desenvolvimento Regional, Universidade Federal do Tocantins (UFT), Palmas, Brasil.

${ }^{2}$ Professor no Programa de Mestrado e Doutorado em Desenvolvimento Regional, Universidade Federal do

Tocantins (UFT), Palmas, Brasil.

${ }^{3}$ Doutorando em Desenvolvimento Regional pela Universidade Federal do Tocantins (UFT) de Palmas, Professor no Instituto Federal de Educação, Ciência e Tecnologia do Maranhão (IFMA), Carolina, Brasil

*Correspondência: Programa de Pós-Graduação em Desenvolvimento Regional, Universidade Federal do Tocantins (UFT), Av. NS 15, 109 Norte, Palmas, Tocantins, Brasil. CEP:77.010-090. e-mail:

fernando.versaocontabil@hotmail.com.

\section{RESUMO}

Esta pesquisa analisou a situação financeira do estado do Tocantins sob a ótica das receitas e despesas por categoria econômica de 2010 a 2015. Para esse fim amparou-se metodologicamente na análise qualitativa e quantitativa, fundada na pesquisa tipo exploratória e descritiva, por meio dos dados obtidos nos demonstrativos do Balanço Geral do governo do estado. A análise da execução orçamentária iniciou-se com um confronto entre as receitas orçadas e arrecadadas, e as despesas fixadas e executadas. Após, apresenta-se a evolução e composição das receitas e despesas de modo geral e nas subcategorias econômicas. Dentre os resultados alcançados, constatou-se que o aumento do gasto público está concentrado nas despesas correntes (92\%), principalmente com Pessoal e Encargo Social, cerca de $60 \%$ do total dos gastos, mas dentro dos limites estabelecidos pela LRF. Conclui-se que em todos os períodos analisados o estado do Tocantins obteve superávit orçamentário, evidenciando que as receitas arrecadadas são superiores ao valor das despesas empenhadas nos exercícios e demonstrando equilíbrio entre os referidos valores.

Palavras-chave: Orçamento público; receitas orçamentárias; despesas orçamentárias.

\section{ABSTRACT}

This research analyzed the financial situation of the state of Tocantins from the perspective of income and expenses by economic category from 2010 to 2015. For this purpose, it was supported methodologically in qualitative and quantitative analysis, based on exploratory and descriptive research, using data obtained in the statements of the General Balance of the state government. The analysis of budget execution started with a comparison between budgeted and collected revenues, and fixed and executed expenses. Afterwards, the evolution and composition of revenues and expenses in general and in the economic subcategories is presented. Among the results achieved, it was found that the increase in public spending is concentrated in current expenses (92\%), mainly with Personnel and Social Charges, about $60 \%$ of total expenses, but within the limits established by the LRF. It is concluded that in all the periods analyzed, the state of Tocantins obtained a budget surplus, showing that the revenues collected are higher than the amount of expenditures committed in the years and demonstrating balance between those amounts.

Keywords: Public budget; budgetary revenue; budgetary expenses. 


\section{RESUMEN}

Esta investigación analizó la situación financiera del estado de Tocantins desde la perspectiva de ingresos y gastos por categoría económica de 2010 a 2015. Para este propósito, se apoyó metodológicamente en análisis cualitativo y cuantitativo, basado en investigación exploratoria y descriptiva, utilizando datos obtenido en las declaraciones del Balance General del gobierno del estado. El análisis de la ejecución del presupuesto comenzó con una comparación entre los ingresos presupuestados y recaudados, y los gastos fijos y ejecutados. Posteriormente, se presenta la evolución y composición de los ingresos y gastos en general y en las subcategorías económicas. Entre los resultados obtenidos, se encontró que el aumento del gasto público se concentra en los gastos corrientes (92\%), principalmente con Cargos de Personal y Sociales, alrededor del $60 \%$ de los gastos totales, pero dentro de los límites establecidos por el LRF. Se concluye que en todos los períodos analizados, el estado de Tocantins obtuvo un superávit presupuestario, lo que demuestra que los ingresos recaudados son superiores a la cantidad de gastos comprometidos en los años y demuestra el equilibrio entre esas cantidade.

Descriptores: Presupuesto público; ingresos presupuestarios; gastos presupuestarios.

\section{INTRODUÇÃO}

O Tocantins é participante direto dos recursos dispostos pela união destinados aos entes nacionais. Criado em 1988 pela Assembleia Nacional Constituinte, instalado oficialmente no dia $1^{\circ}$ de janeiro de 1989 e em 20 de maio foi fundada a capital planejada, Palmas. Localiza-se na região Norte, exatamente no centro geográfico do país, condição que lhe possibilita fazer limite com os estados: Goiás (Sul); Piauí (Leste); Maranhão (Nordeste); Bahia (Sudeste); Pará (Noroeste) e Mato Grosso (Sudoeste), em uma área de encontro de três biomas: Amazônia, Pantanal e Cerrado. A extensão territorial do estado de Tocantins é de 277.620,9 km² (TOCANTINS, 2016).

O estado conta com 139 municípios - as principais cidades do estado, além da capital Palmas, são: Araguaína, Gurupi, Porto Nacional, Paraíso do Tocantins, Araguatins, Colinas do Tocantins, Miracema do Tocantins, Tocantinópolis e Guaraí -e com uma população de 1.515 .126 habitantes (estimativa do IBGE para 2015); o que representa 0,74\% da população do Brasil. Densidade demográfica $5,45\left(\mathrm{hab} / \mathrm{km}^{2}\right)$; rendimento nominal mensal domiciliar per capita de R\$ 818. (TOCANTINS, 2016).

Objetivo geral é analisar a situação financeira do Estado do Tocantins sob a ótica das receitas e despesas por categoria econômica entre 2010 e 2015.
Os objetivos específicos são: analisar comparativamente a receita orçada com a arrecadada e as despesas previstas com a realizada; avaliar a participação de cada componente na composição das receitas e despesas orçamentárias; identificar a capacidade de investimento do governo.

Justifica-se este estudo pois, o aumento das inúmeras demandas sociais, reflexo da maior complexidade das relações socioeconômicas, face à escassez dos recursos econômicos, exige cada vez mais do Estado à adoção de medidas estratégicas à sua rotina de planejamento e execução da alocação dos recursos.

À vista disso, a gestão pública se defronta com a necessidade de obter certa previsibilidade de cenários futuros com vistas ao atendimento das necessidades dos agentes sociais. Portanto, esta pesquisa se justifica dada a importância e o caráter dinâmico das finanças públicas que se constituem a principal peça de atuação dos governos e por meio das quais instituem as prioridades no tocante à prestação dos serviços públicos e aos investimentos a serem executados.

\section{TEORIA DAS RECEITAS E DESPESAS PÚBLICAS}

A teoria das finanças públicas aborda sobre os fundamentos do Estado e das Funções de governo, e dá suporte teórico (fundamentação) à intervenção do 
Estado na economia. De forma geral, a teoria gira em torno da existência das falhas de mercado que torna necessária a presença do Governo, o estudo das funções do Governo, da teoria da tributação e do gasto público. As falhas de mercado são fenômenos que impedem que a economia alcance o estágio de Estado de Bem-Estar Social, através do livre mercado, sem interferência do Governo (PALUDO, 2012).

As falhas de mercado, segundo Pindyck e Rubinfeld (2010, p. 575), são:

- Existência dos bens públicos: bens que podem beneficiar todos os consumidores, mas cuja oferta no mercado ou é insuficiente ou é totalmente inexistente. Os bens públicos são de consumo indivisível e não excludente. São consumidos por diversas pessoas ao mesmo tempo (ex.: rua, praça, segurança pública, justiça).

- Existência de monopólios naturais: monopólios que tendem a surgir devido ao ganho de escala que o setor oferece (ex.: água, energia elétrica). O governo acaba sendo obrigado a assumir a produção ou criar agências que impeçam a exploração dos consumidores.

- Externalidades: são os efeitos das atividades de produção e consumo que não se refletem diretamente no mercado. Há externalidades negativas - que ocorre quando a ação de uma das partes impõe custos à outra - e externalidades positivas - que surgem quando a ação de uma das partes beneficia a outra. Como exemplo, uma fábrica pode poluir um rio e ao mesmo tempo gerar empregos. Assim, a poluição é uma externalidade negativa porque causa danos ao meio ambiente e à geração de empregos, e é uma externalidade positiva por aumentar o bem-estar e a renda. O governo deverá agir no sentido de inibir atividades que causem externalidades negativas e incentivar atividades causadoras de externalidades positivas;

- Desenvolvimento, emprego e estabilidade: há regiões que não se desenvolvem sem a ação do Estado - principalmente nas economias em desenvolvimento a ação governamental é muito importante no sentido de gerar crescimento econômico através de bancos de desenvolvimento, como o BNDES (Banco Nacional de Desenvolvimento Econômico e Social), criar postos de trabalho e buscar a estabilidade econômica.

Para que o Estado atinja o objetivo de suprir às principais demandas da sociedade, esse dispõe do direito, através de aprovação parlamentar, de arrecadar recursos constituídos por proventos, créditos e outros ingressos. Esses recursos integram a denominada receita pública. Assim, esta secção tem por objetivo descrever os diversos conceitos existentes sobre receitas públicas, suas classificações e composição nas subcategorias econômicas, e as etapas da receita no processo orçamentário.

O Manual de Receita Nacional STN/SOF (2008, p. 21) define como receita "todos os ingressos disponíveis para cobertura das despesas orçamentárias e operações que, mesmo não havendo ingresso de recursos, financiam despesas orçamentárias”.

Os gastos públicos podem ser conceituados como uma escolha política dos governos no que se refere aos diversos serviços que prestam à sociedade. Representam o custo da quantidade e da qualidade dos serviços e bens oferecidos pelo governo. A interpretação mais usual dos gastos públicos considera o custo da provisão dos bens e serviços executados pelo setor público que aparece nas contas orçamentárias (RIANI, 2009). 
De acordo com Riani (2009), no estudo das finanças públicas, existe uma diferenciação básica entre os chamados gastos governamental e os gastos públicos. Consideram-se gastos governamentais apenas as despesas realizadas pelas unidades que compõem a administração governamental direta e indireta. Dessa forma, seriam englobados nesse conceito apenas os gastos realizados pelas esferas de governo mais suas autarquias e fundações. Por outro lado, considera-se gasto público a totalidade dos gastos governamentais mais as despesas do governo com suas atividades econômicas produtivas, incluindo-se aí as empresas estatais.

A contribuição de Adolph Wagner ao estudo do crescimento e das despesas públicas é sintetizada na chamada "Lei de Wagner", ou "lei dos dispêndios públicos crescentes" que estabelece a seguinte proposição: “À medida que cresce o nível de renda em países industrializados, o setor público cresce sempre a taxas mais elevadas, de tal forma que a participação relativa do governo na economia cresce com o próprio ritmo de crescimento econômico do país". As razões apontadas para a formulação de tal hipótese são de três tipos. (REZENDE, 2007).

\section{MATERIAIS E MÉTODOS}

Esta pesquisa concentrou-se em analisar a situação financeira do Estado do Tocantins a partir das receitas e despesas orçamentárias classificadas segundo a sua categoria econômica. Para tanto, a fim de atender a problemática do trabalho, isto é, estudar a estrutura orçamentária quanto a sua programação e execução, desenvolveu-se uma análise qualitativa e quantitativa, fundada na pesquisa tipo exploratória e descritiva.

A pesquisa exploratória faz-se necessário para contextualizar o desempenho das variáveis em estudo em contraste com os aspectos teóricos que integraram o interstício da análise. A descritiva ocupou-se de registrar e analisar dados e informações secundárias referentes ao balanço orçamentário.

Ainda, fez-se a análise da execução orçamentária por meio do Quociente do Resultado Orçamentário, no qual segundo Kohama (2011), é resultante da relação entre a Receita Realizada e a Despesa Executada, indicando a existência de superávit ou déficit. Esse quociente deve demonstrar quanto da Receita Realizada serve de cobertura para a Despesa Executada.

Interpretação do quociente:

- 1 = Receita Realizada é igual à Despesa Executada.

- Maior do que 1 = Receita Realizada é maior do que a Despesa Executada, portanto, a diferença representa um superávit.

- Menor do que 1 = Receita Realizada é menor do que a Despesa Executada, portanto, a diferença representa um déficit.

No sentido de coletar mais informações e detalhes que permitem auxiliar na análise e interpretação do resultado orçamentário, utiliza-se o Quociente Financeiro Real da Execução Orçamentário, com o objetivo de igualar a escrituração da receita orçamentária e despesa orçamentária, pelo regime de caixa, o que será feito retirando-se os restos a pagar inscritos no exercício. Essa providência será de extrema utilidade para se entender, com maiores condições, o resultado do Balanço Orçamentário, que nele se demonstrar déficit orçamentário de execução (KOHAMA, (2011).

Temos a seguinte interpretação desse quociente, conforme Kohama (2011):

- 1 = Receita Orçamentária igual à Despesa Orçamentária menos (os Restos a Pagar 
inscritos no exercício somados com o Serviço da Dívida, que são as parcelas de amortização e de juros da dívida fundada a pagar que passa para o exercício seguinte). Essa hipótese demonstrará haver igualdade na execução orçamentária e financeira.

- Maior do que 1 = Receita Orçamentária maior do que a Despesa Orçamentária menos (os Restos a Pagar inscritos no exercício somados com o Serviço da Dívida a pagar que passa para o exercício seguinte). Essa hipótese refletirá que existe superávit na execução orçamentária e financeira.

- Menor do que 1 = Receita Orçamentária menor do que a Despesa Orçamentária menos (os Restos a Pagar inscritos no exercício somados com o Serviço da Dívida a pagar que passa para o exercício seguinte). Essa hipótese significará que, mesmo usando o regime de caixa também para as Despesas Orçamentárias, haverá déficit na execução orçamentária e financeira.

Dever-se-á considerar normal o resultado 1 e bom o maior que 1 . Caso o resultado seja menor do que 1 , deve ser considerado preocupante, pois a receita arrecadada será menor do que a despesa paga, pressupondo-se a utilização de recursos financeiros provenientes da receita extra orçamentária para sua cobertura.

Para cumprir com os objetivos propostos por este trabalho foi realizada pesquisas em livros, periódicos, artigos, dissertações, teses e em sítios eletrônicos pertencentes ao ente público pesquisado. Em uma primeira etapa, que ocorreu no primeiro semestre de 2016, houve a transposição dos dados dos demonstrativos emitidos pelo Governo do Estado, obtidos por intermédio do sítio eletrônico do Portal da Transparência do Estado do Tocantins, nos Balanços Gerais do Estado, especificamente nos demonstrativos da Lei $\mathrm{n}^{\circ} 4.320 / 1964$, referentes ao período de 2010 a 2015. Em um segundo momento, houve a tabulação, interpretação e análise dos dados.

\section{RESULTADOS E DISCUSSÃO}

A Tabela 1, apresenta as receitas consolidadas arrecadadas pelo Estado do Tocantins no período de 2010 a 2015. Destaca-se que as receitas dispostas nesta pesquisa, pertencem ao Balanço Geral consolidado do Estado do Tocantins, ou seja, englobam as receitas dos três Poderes do Estado (Executivo, Legislativo e Judiciário), no seu conjunto de órgãos da Administração Direta, Fundos Especiais, Autarquias, Fundações e Empresas Estatais dependentes.

Em análise dos dados consolidados presente na tabela 1, nota-se que há uma arrecadação crescente no período analisado. As receitas orçamentárias arrecadadas em 2010 atingiram $\mathrm{R} \$ 4,8$ bilhões, e nos anos subsequentes esse montante foi cada vez maior, chegando a $\mathrm{R} \$ 8,1$ bilhões em 2015. Ainda, de acordo com os dados, as receitas orçamentárias em 2015 tiveram variação de $66 \%$ em relação ao ano de 2010 , em termos reais (descontada a inflação), porém, as receitas aumentaram 55,3\%, impulsionadas pelo aumento de 25\% das Transferências Correntes - esta que corresponde a $45 \%$ das receitas totais.

Já em termos relativos aquelas que obtiveram um expressivo acréscimo foram as Receitas de Serviços e de Contribuição, com $1.118 \%$ e $258 \%$ respectivamente. 
Tabela 1. Receitas orçamentárias arrecadadas.

\begin{tabular}{|c|c|c|c|c|c|c|}
\hline EXERCÍCIO & 2010 & 2011 & 2012 & 2013 & 2014 & 2015 \\
\hline Receitas Orçamentárias & 4.898.315 & 5.356 .678 & 6.349 .905 & 6.534.550 & 7.461 .668 & 8.132.122 \\
\hline Receitas Correntes & 4.351.108 & 5.116 .903 & 5.645 .649 & 6.034.604 & 6.907 .556 & 7.685 .400 \\
\hline Receitas Tributárias & 1.394 .655 & 1.695 .192 & 1.912 .664 & 2.212 .458 & 2.465 .111 & 2.396 .604 \\
\hline Receita de Contribuições & 243.512 & 296.252 & 327.554 & 353.981 & 416.277 & 872.903 \\
\hline Receita Patrimonial & 271.863 & 340.949 & 520.788 & 323.122 & 607.016 & 514.084 \\
\hline Receita Agropecuária $^{1}$ & - & - & - & - & - & - \\
\hline Receita Industrial & - & - & - & - & - & - \\
\hline Receita de Serviços & 2.030 & 2.324 & 5.195 & 21.677 & 45.010 & 38.950 \\
\hline Transferências Correntes & 2.975 .360 & 3.472 .980 & 3.591 .758 & 3.902 .255 & 4.200 .132 & 3.729 .065 \\
\hline Outras Receitas Correntes & 56.213 & 57.829 & 74.377 & 78.591 & 91.668 & 133.791 \\
\hline Receitas de Capital & 547.207 & 239.775 & 704.256 & 499.946 & 554.112 & 446.722 \\
\hline Operações de Crédito & 360.416 & 167.710 & 564.134 & 364.967 & 413.430 & 366.714 \\
\hline Alienação de Bens & 43.649 & 13.246 & 15.706 & 50.364 & 23.778 & 10.681 \\
\hline $\begin{array}{l}\text { Amortização de } \\
\text { Empréstimos }\end{array}$ & 7.279 & 5.494 & 10.342 & 14.494 & 16.495 & 11.832 \\
\hline Transferências de Capital & 135.868 & 53.324 & 114.076 & 70.224 & 100.422 & 10.525 \\
\hline Outras Receitas de Capital & - & - & - & - & - & - \\
\hline
\end{tabular}

Fonte: Adaptado do Balanço Geral do Estado do Tocantins (Dados originais em milhares R\$)*.

As variações percentuais das receitas para o ano de 2012 que teve aumento percentual de orçamentárias foram todas positivas, conforme demonstra o gráfico 1.

O Gráfico 1 evidencia que as receitas orçamentárias tiveram uma tendência de ascensão e queda em termos relativos, entretanto em termos absolutos houve em todo o período analisado o 18,54 em relação a 2011, em termos absolutos o maior aumento ocorreu no mesmo ano, com o incremento de cerca de $\mathrm{R} \$ 993$ milhões em receitas, isto em decorrência do aumento na arrecadação das Operações de Crédito e nas Receitas de Serviços, ou seja o estado contraiu mais empréstimos no sistema financeiro.

crescimento das receitas arrecadadas com destaque

Gráfico 1. Variação Percentual das Receitas Orçamentárias arrecadadas.

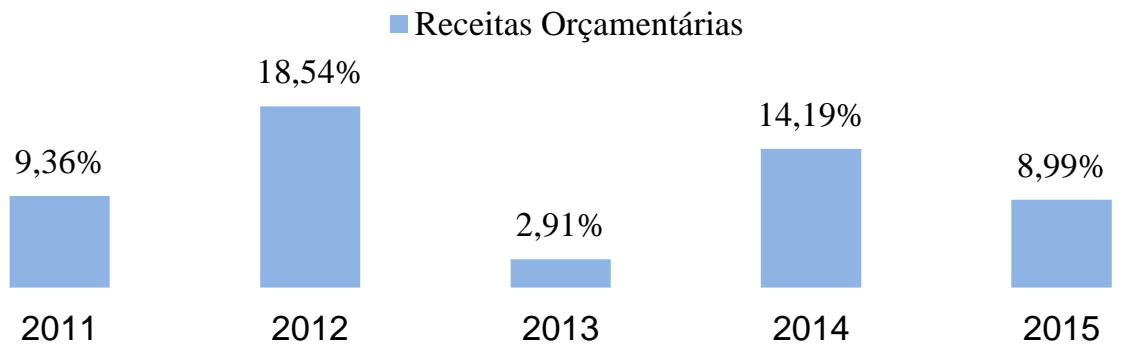

Fonte: Adaptado do Balanço Geral do Estado do Tocantins (Dados originais em milhares R\$).

A menor variação relativa foi no ano de 2013, com crescimento moderado de $2,91 \%$, o que se explica diante das perdas de receita nas Transferências de Capital, Receitas Patrimoniais e Operações de Créditos.
A Tabela 2 apresenta as despesas consolidadas pagas pelo Estado do Tocantins no período de 2010 a 2015 .

1 Segundo informações obtidas na secretaria do Planejamento e Orçamento do Tocantins, as subcategorias Receita Agropecuária, Industrial, e Outras Receitas de Capitais são receitas de configuram os recursos próprios das autarquias e demais entidades da Administração Indireta, portanto não se apresentam no balanço geral do governo do estado. 
Tabela 2. Despesas orçamentárias pagas.

\begin{tabular}{ccccccc}
\hline EXERCÍCIO & $\mathbf{2 0 1 0}$ & $\mathbf{2 0 1 1}$ & $\mathbf{2 0 1 2}$ & $\mathbf{2 0 1 3}$ & $\mathbf{2 0 1 4}$ & $\mathbf{2 0 1 5}$ \\
\hline Despesas Orçamentárias & $\mathbf{4 . 4 8 6 . 7 5 1}$ & $\mathbf{4 . 8 8 0 . 2 6 6}$ & $\mathbf{5 . 4 2 7 . 4 6 3}$ & $\mathbf{6 . 1 9 8 . 1 8 5}$ & $\mathbf{6 . 9 5 2 . 1 7 9}$ & $\mathbf{7 . 2 3 3 . 0 5 2}$ \\
\hline Despesas Correntes & $\mathbf{3 . 5 0 6 . 8 6 6}$ & $\mathbf{4 . 1 9 1 . 9 1 8}$ & $\mathbf{4 . 7 1 0 . 8 2 3}$ & $\mathbf{5 . 2 5 9 . 4 7 7}$ & $\mathbf{5 . 7 6 2 . 2 0 3}$ & $\mathbf{6 . 6 5 4 . 2 4 2}$ \\
\hline Pessoal e Encargo social & 1.971 .431 & 2.466 .061 & 2.691 .046 & 3.025 .142 & 3.128 .082 & 4.386 .118 \\
\hline Juros e Encargos da Dívida & 49.353 & 60.435 & 71.467 & 101.529 & 111.042 & 157.278 \\
\hline Outras Despesas Correntes & 1.486 .082 & 1.665 .421 & 1.948 .310 & 2.132 .805 & 2.523 .079 & 2.110 .844 \\
\hline Despesas de Capital & $\mathbf{9 7 9 . 8 8 5}$ & $\mathbf{6 8 8 . 3 4 8}$ & $\mathbf{7 1 6 . 6 4 0}$ & $\mathbf{9 3 8 . 7 0 8}$ & $\mathbf{1 . 1 8 9 . 9 7 6}$ & $\mathbf{5 7 8 . 8 1 0}$ \\
\hline Investimentos & 872.535 & 536.756 & 547.008 & 675.775 & 940.507 & 244.536 \\
\hline Inversões Financeiras & 11.974 & 25.733 & 13.398 & 35.062 & 17.644 & 8.749 \\
\hline Amortização da Dívida & 95.375 & 125.858 & 156.234 & 227.870 & 231.824 & 325.525 \\
\hline
\end{tabular}

Fonte: Adaptado do Balanço Geral do Estado do Tocantins (Dados originais em milhares R\$)*.

Em análise dos dados consolidados, tabela 2, nota-se que as despesas orçamentárias obtiveram crescimentos consecutivos no período analisado. As despesas orçamentárias pagas em 2010 atingiram R \$ 4,4 bilhões, e nos anos posteriores esse montante aumentou $61,21 \%$, chegando a $\mathrm{R} \$ 7,2$ bilhões em 2015. Esta ampliação das despesas ocorreu em virtude, principalmente, do aumento em $122,48 \%$ dos gastos com Pessoal e Encargos Sociais, componente este de despesa que corresponde a 60,64\% do total dos gastos. Nota-se ainda, que em termos relativos os maiores gastos foram com Amortização da Dívida, e Juros e Encargos da Dívida, sendo $241 \%$ e $218 \%$ de variação de 2010/2015, respectivamente.

As variações percentuais das despesas orçamentárias foram todas positivas, conforme gráfico 2.

Gráfico 2. Variação Percentual das Despesas Orçamentárias pagas.

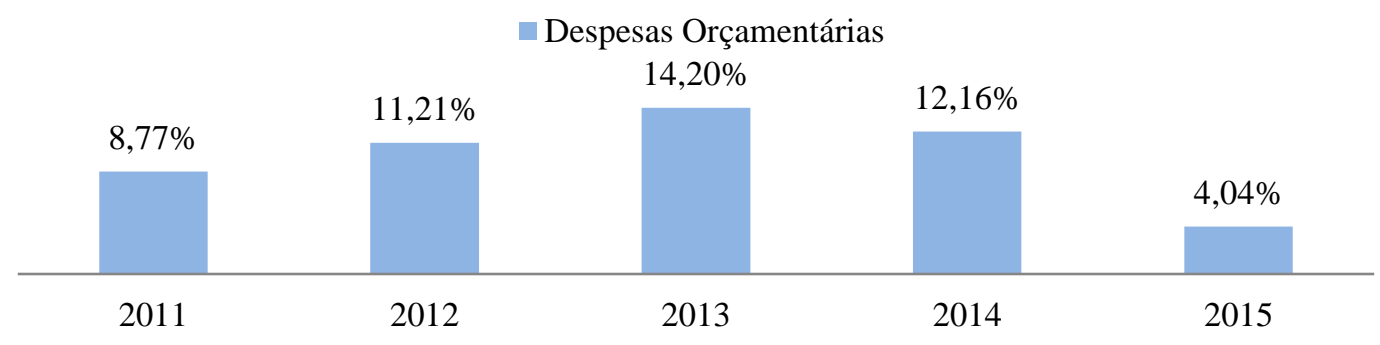

Fonte: Adaptado do Balanço Geral do Estado do Tocantins.

Observa-se, que as despesas orçamentárias, apresentam uma tendência de crescimento relativo, com destaque para o ano de 2013 que teve variação de $14,20 \%$, resultado este de maiores gastos nas Inversões Financeiras $(161,70 \%)$ e Amortização da Dívida (45,85\%). Entretanto em 2014 e 2015 esta tendência não se manteve, pois ocorreu queda na variação dos gastos, neste último, as despesas cresceram apenas $4,04 \%$, os maiores gastos se deram com Pessoal e
Encargos Sociais, destaca-se que o componente de maior queda foi os Investimentos (-74\%).

Em termos absolutos houve evolução do montante das despesas pagas, tendo como maior aumento os R \$ 754 milhões de gastos em 2014.

A execução das despesas e receitas, quanto aos valores absolutos pagos e arrecadados conjuntamente assim se apresentou de 2010 a 2015, conforme gráfico 3. 
Gráfico 3. Despesas e Receitas Orçamentárias consolidadas.

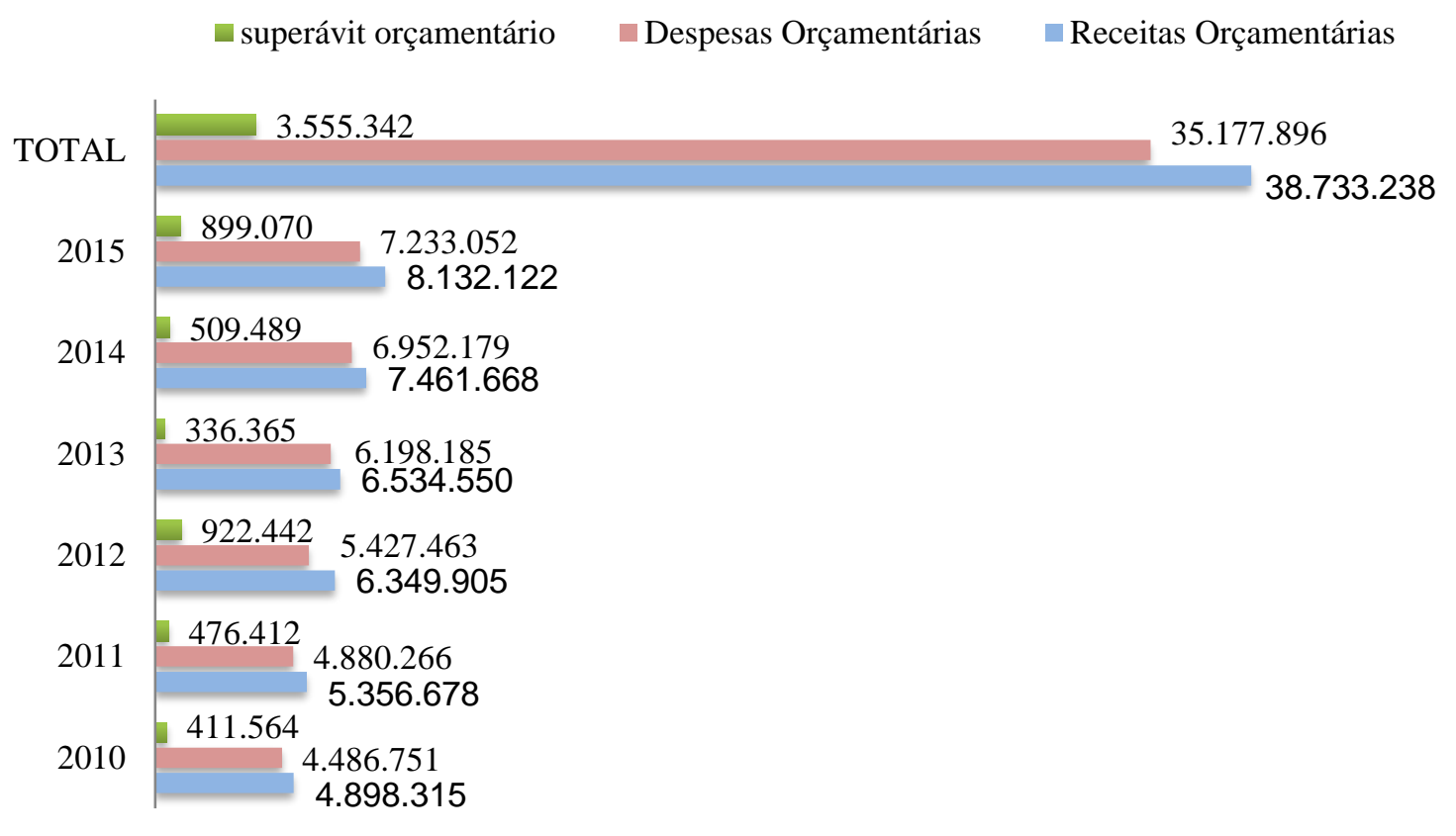

Fonte: Adaptado do Balanço Geral do Estado do Tocantins (Dados originais em milhares R\$).

Quanto à análise global do resultado orçamentário, verifica-se que, confrontando a receita arrecadada ( $\mathrm{R} \$ 38,7$ bilhões) com a despesa executada (R \$ 35,1 bilhões), constata-se que, no período analisado, o Estado do Tocantins obteve um superávit orçamentário no valor de $\mathrm{R} \$ 3,5$ bilhões, evidenciando que as receitas arrecadadas são superiores ao valor das despesas empenhadas no exercício e demonstrando equilíbrio entre os referidos valores, ou seja, para cada $\mathrm{R} \$ 1,00$ de receita arrecadada houve uma despesa executada de $\mathrm{R} \$ 0,90$.

De acordo com os dados contidos no gráfico 3, o Estado apresentou resultado orçamentário superavitário, com destaque para os anos de 2012 e 2015, no qual obteve-se um superávit orçamentário no valor de R\$ 922,4 milhões e R\$ 899 milhões respectivamente.

O Quociente do Resultado Orçamentário é resultante da relação entre a Receita Realizada e a Despesa Executada, indicando a existência de superávit ou déficit.

Assim, de acordo com o quociente orçamentário, o Estado apresenta resultado orçamentário superavitário da Administração Direta, como pode ser observado no gráfico 4 .

Gráfico 4. Quociente do resultado orçamentário.

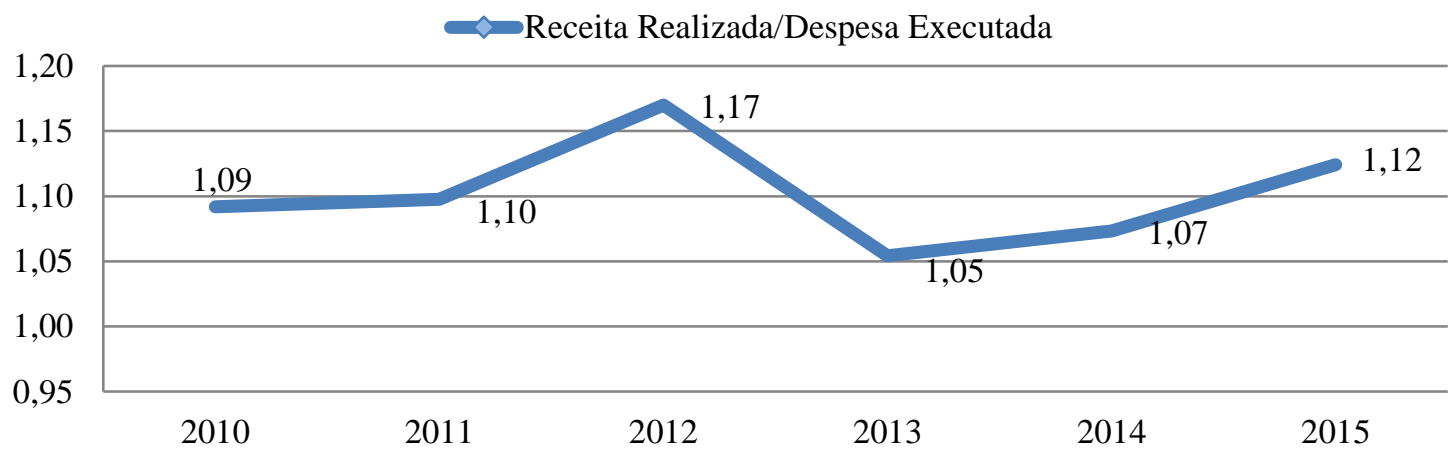

Fonte: Adaptado do Balanço Geral do Estado do Tocantins. 
Este quociente revela que em todos os anos estudados, a receita executada foi sempre maior que a despesa executada, pois o quociente foi maior que um, evidenciando superávits.

O quociente que mais se destacou foi o do ano de 2012 , porque existia $\mathrm{R} \$ 1,17$ de receita executada para cada $\mathrm{R} \$ 1,00$ de despesa paga, gerando um superávit de execução. Isto ocorreu principalmente, em virtude do crescimento da receita tributária e da utilização de operações de créditos.
$\mathrm{Na}$ análise executada neste quociente percebese que nos últimos três anos analisados, os seus resultados evidenciam uma tendência de crescimento. Enfim, estes resultados dos quocientes do balanço orçamentário apresentam uma situação positiva. Sobre o quociente financeiro real da execução orçamentária, esse demonstra quanto a receita orçamentária recebida representa em relação à despesa orçamentária paga, consideradas pelo regime de caixa, pois é descontado os valores dos Restos a Pagar inscritos no exercício.

Gráfico 5. Quociente financeiro real.

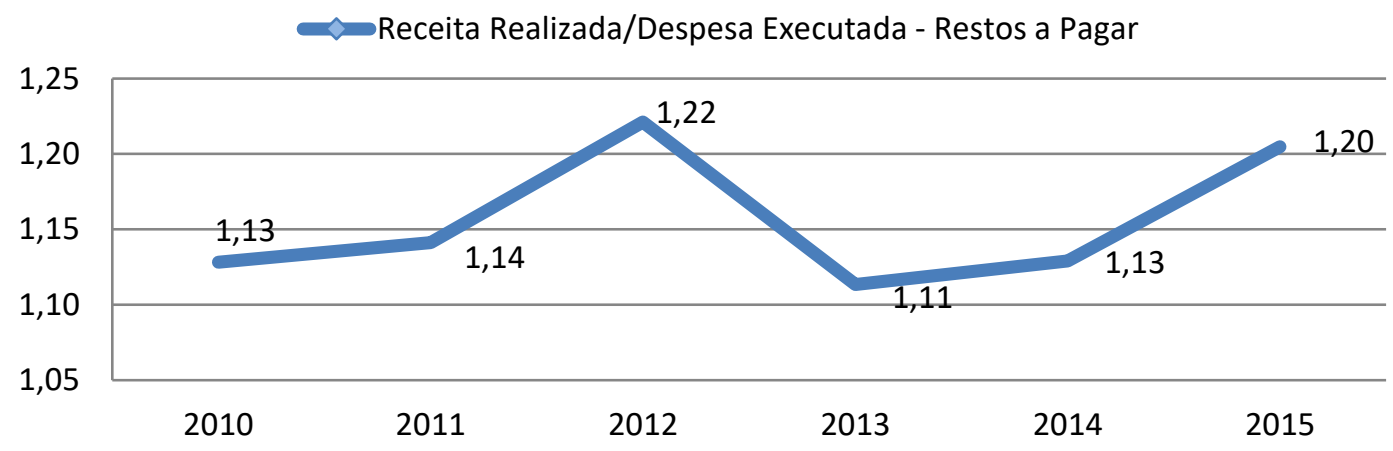

Fonte: Adaptado do Balanço Geral do Estado do Tocantins.

De acordo com o gráfico 5, o quociente evidencia que no ano de 2010 teve-se 1,13 de receita orçamentária recebida para cada 1,00 de despesa orçamentária paga. Assim, entendendo-se a despesa orçamentária paga, como a equiparação da escrituração pelo regime de caixa, verifica-se que houve superávit, agora com um montante maior.

Tal apontamento se repete nos demais anos, com destaque para 2013, 2014 e 2015, nos quais os quocientes financeiros demonstraram um resultado mais elevado, quando comparados com o quociente anterior. Em virtude, principalmente, pelo aumento do valor de restos a pagar e dos serviços da dívida destes exercícios. Demonstrando assim uma grande margem de superávit na execução orçamentária.

Para iniciar a análise da evolução e composição das Receitas e Despesas Orçamentárias, assim como a capacidade de investimento do Estado do Tocantins, considera-se importante a análise comparativa da receita orçada com a arrecadada, conforme se apresenta no Quadro 1 seguinte.

Quadro 1. Receita Orçamentária Prevista e Arrecadada.

\begin{tabular}{|c|c|c|c|}
\hline EXERCÍCIO & PREVISÃO & ARRECADAÇÃO & $\%$ \\
\hline 2010 & 5.989 .782 & 4.898 .315 & $82 \%$ \\
\hline 2011 & 6.242 .524 & 5.356 .678 & $86 \%$ \\
\hline 2012 & 7.484 .527 & 6.349 .905 & $85 \%$ \\
\hline 2013 & 7.732 .749 & 6.534 .550 & $85 \%$ \\
\hline 2014 & 8.782 .625 & 7.461 .668 & $85 \%$ \\
\hline 2015 & 9.735 .886 & 8.132 .122 & $84 \%$ \\
\hline
\end{tabular}

Fonte: Adaptado do Balanço Geral do Estado do Tocantins (Dados originais em milhares R\$). 
Observa-se, no quadro 1, que a receita arrecadada em relação à receita prevista nos exercícios em análise não foi atingida em nenhum dos anos estudados. Apura-se ainda, que houve arrecadação a menor das receitas em média $15,5 \%$ da receita prevista.

Percebe-se que na elaboração do orçamento no que tange a previsão total das Receitas Orçamentárias, não vem se aperfeiçoando, uma vez que em 2010 o índice de execução orçamentário foi $82 \%$, e nos anos posteriores o percentual teve uma pequena elevação, mas manteve-se quase constante. $\mathrm{O}$ governo sempre teve uma expectativa de aumento de receitas, mas na prática isto não ocorreu.

A seguir apresenta-se a tabela 3 com os valores da execução das receitas distribuídas nas categorias econômicas de 2010 a 2015.

Tabela 3. Demonstrativo da receita orçada com a arrecadada.

\begin{tabular}{|c|c|c|c|c|c|c|}
\hline \multirow[t]{2}{*}{ EXERCÍCIO } & \multicolumn{3}{|c|}{2010} & \multicolumn{2}{|l|}{2011} & 2012 \\
\hline & Orçada & Arrecadada & Orçada & Arrecadada & Orçada & Arrecadada \\
\hline Receitas Orçamentárias & 5.989 .782 & 4.898.315 & 6.242 .524 & 5.356 .678 & 7.484.527 & 6.349 .905 \\
\hline Receitas Correntes & 4.625 .442 & 4.351.108 & 5.182 .692 & 5.116 .903 & 5.961 .218 & 5.645 .649 \\
\hline Receitas Tributárias & 1.501 .328 & 1.394 .655 & 1.571 .332 & 1.695 .192 & 1.842 .076 & 1.912 .664 \\
\hline Receita de Contribuições & 218.651 & 243.512 & 312.962 & 296.252 & 306.623 & 327.554 \\
\hline Receita Patrimonial & 256.205 & 271.863 & 203.922 & 340.949 & 365.330 & 520.788 \\
\hline Receita de Serviços & 2.375 & 2.030 & 3.313 & 2.324 & 5.674 & 5.195 \\
\hline Transferências Correntes & 3.263 .668 & 2.975 .360 & 3.775 .717 & 3.472 .980 & 4.203 .166 & 3.591 .758 \\
\hline Outras Receitas Correntes & 45.489 & 56.213 & 64.731 & 57.829 & 67.276 & 74.377 \\
\hline Receitas de Capital & 1.364 .340 & 547.207 & 1.059 .832 & 239.775 & 1.523.309 & 704.256 \\
\hline Operações de Crédito & 777.139 & 360.416 & 457.615 & 167.710 & 907.536 & 564.134 \\
\hline Alienação de Bens & 42.705 & 43.649 & 50.081 & 13.246 & 12.023 & 15.706 \\
\hline $\begin{array}{l}\text { Amortização de } \\
\text { Empréstimos }\end{array}$ & 11.054 & 7.279 & 23.101 & 5.494 & 21.946 & 10.342 \\
\hline Transferências de Capital & 533.441 & 135.868 & 529.033 & 53.324 & 581.803 & 114.076 \\
\hline $\begin{array}{c}\text { Outras Receitas de } \\
\text { Capital }\end{array}$ & - & - & - & - & - & - \\
\hline \multirow[t]{2}{*}{ EXERCÍCIO } & & 2013 & & 2014 & & 2015 \\
\hline & Orçada & Arrecadada & Orçada & Arrecadada & Orçada & Arrecadada \\
\hline Receitas Orçamentárias & 7.732 .749 & 6.534 .550 & 8.782 .625 & 7.461 .668 & 9.735 .886 & 8.132 .122 \\
\hline Receitas Correntes & 6.262 .033 & 6.034 .604 & 7.097.599 & 6.907 .556 & 8.551 .465 & 7.685.400 \\
\hline Receitas Tributárias & 2.099 .799 & 2.212 .458 & 2.350 .030 & 2.465 .111 & 2.294 .365 & 2.396 .604 \\
\hline Receita de Contribuições & 373.315 & 353.981 & 398.137 & 416.277 & 1.318 .818 & 872.903 \\
\hline Receita Patrimonial & 430.077 & 323.122 & 521.034 & 607.016 & 644.667 & 514.084 \\
\hline Receita de Serviços & 41.232 & 21.677 & 42.827 & 45.010 & 52.677 & 38.950 \\
\hline Transferências Correntes & 4.101 .391 & 3.902 .255 & 4.674 .275 & 4.200 .132 & 4.089 .382 & 3.729 .065 \\
\hline Outras Receitas Correntes & 68.061 & 78.591 & 91.179 & 91.668 & 151.553 & 133.791 \\
\hline Receitas de Capital & 1.470 .716 & 499.946 & 1.685 .026 & 554.112 & 1.184 .421 & 446.722 \\
\hline Operações de Crédito & 862.813 & 364.967 & 1.008 .482 & 413.430 & 796.026 & 366.714 \\
\hline Alienação de Bens & 48.189 & 50.364 & 25.617 & 23.778 & 13.109 & 10.681 \\
\hline $\begin{array}{l}\text { Amortização de } \\
\text { Empréstimos }\end{array}$ & 36.800 & 14.494 & 34.000 & 16.495 & 35.000 & 11.832 \\
\hline Transferências de Capital & 522.913 & 70.224 & 616.927 & 100.422 & 340.284 & 10.525 \\
\hline
\end{tabular}

Outras Receitas de Capital

Fonte: Adaptado do Balanço Geral do Estado do Tocantins (Dados originais em milhares R\$). 
Diante destes dados distribuídos nas categorias econômicas, têm-se as seguintes diferenças percentuais na execução das receitas arrecadadas em relação às receitas orçadas, demonstrado na Tabela 4.

No confronto das Receitas Correntes totais, na tabela 4, a maior diferença da arrecadação em relação à previsão, ocorreu no ano de 2015, com percentual de $10,13 \%$ a menor. Nota-se que variações negativas também ocorreram nos anos anteriores, porém, com os percentuais moderados de 1,27\% em 2011 e 2,68\% em 2014.

Tabela 4. Diferença percentual da execução da receita arrecadada em relação à receita orçada.

\begin{tabular}{ccccccc}
\hline EXERCÍCIO & $\mathbf{2 0 1 0}$ & $\mathbf{2 0 1 1}$ & $\mathbf{2 0 1 2}$ & $\mathbf{2 0 1 3}$ & $\mathbf{2 0 1 4}$ & $\mathbf{2 0 1 5}$ \\
\hline Receitas Orçamentárias & $\mathbf{- 1 8 , 2 2 \%}$ & $\mathbf{- 1 4 , 1 9 \%}$ & $\mathbf{- 1 5 , 1 6 \%}$ & $\mathbf{- 1 5 , 5 0 \%}$ & $\mathbf{- 1 5 , 0 4 \%}$ & $\mathbf{- 1 6 , 4 7 \%}$ \\
\hline Receitas Correntes & $\mathbf{- 5 , 9 3 \%}$ & $\mathbf{- 1 , 2 7 \%}$ & $\mathbf{- 5 , 2 9 \%}$ & $\mathbf{- 3 , 6 3 \%}$ & $\mathbf{- 2 , 6 8 \%}$ & $\mathbf{- 1 0 , 1 3 \%}$ \\
\hline Receitas Tributárias & $-7,11 \%$ & $7,88 \%$ & $3,83 \%$ & $5,37 \%$ & $4,90 \%$ & $4,46 \%$ \\
\hline Receita de Contribuições & $11,37 \%$ & $-5,34 \%$ & $6,83 \%$ & $-5,18 \%$ & $4,56 \%$ & $-33,81 \%$ \\
\hline Receita Patrimonial & $\mathbf{6 , 1 1 \%}$ & $\mathbf{6 7 , 2 0 \%}$ & $42,55 \%$ & $-24,87 \%$ & $16,50 \%$ & $-20,26 \%$ \\
\hline Receita Agropecuária & - & - & - & - & - & - \\
\hline Receita Industrial & - & - & - & - & - & - \\
\hline Receita de Serviços & $-14,53 \%$ & $-29,85 \%$ & $-8,44 \%$ & $-47,43 \%$ & $5,10 \%$ & $-26,06 \%$ \\
\hline Transferências Correntes & $-8,83 \%$ & $-8,02 \%$ & $-14,55 \%$ & $-4,86 \%$ & $-10,14 \%$ & $-8,81 \%$ \\
\hline Outras Receitas Correntes & $23,57 \%$ & $-10,66 \%$ & $10,56 \%$ & $15,47 \%$ & $0,54 \%$ & $-11,72 \%$ \\
\hline Receitas de Capital & $\mathbf{- 5 9 , 8 9 \%}$ & $\mathbf{- 7 7 , 3 8 \%}$ & $\mathbf{- 5 3 , 7 7 \%}$ & $\mathbf{- 6 6 , 0 1 \%}$ & $\mathbf{- 6 7 , 1 2 \%}$ & $\mathbf{- 6 2 , 2 8 \%}$ \\
\hline Operações de Crédito & $-53,62 \%$ & $-63,35 \%$ & $-37,84 \%$ & $-57,70 \%$ & $-59,00 \%$ & $-53,93 \%$ \\
\hline Alienação de Bens & $2,21 \%$ & $-73,55 \%$ & $30,63 \%$ & $4,51 \%$ & $-7,18 \%$ & $-18,52 \%$ \\
\hline Amortização de Empréstimos & $-34,15 \%$ & $-76,22 \%$ & $-52,88 \%$ & $-60,61 \%$ & $-51,49 \%$ & $-66,19 \%$ \\
\hline Transferências de Capital & $-74,53 \%$ & $-89,92 \%$ & $-80,39 \%$ & $-86,57 \%$ & $-83,72 \%$ & $-96,91 \%$ \\
\hline Outras Receitas de Capital & - & - & - & - & - & -
\end{tabular}

Fonte: Adaptado do Balanço Geral do Estado do Tocantins.

Ainda, exceto o ano de 2015, nos demais, as execuções das Receitas Correntes apresentaram variações percentuais negativas insignificantes, este fator é essencial para manter o equilíbrio do orçamento, uma vez que essa categoria econômica foi responsável por $92 \%$ do total da arrecadação das Receitas Orçamentárias do Estado do Tocantins em todo o período analisado.

Entre as origens de receitas que compõe as Receitas Correntes, a que se destaca pela moderada variação é a Receita Tributária, esta apresenta percentual de diferença positiva em cinco dos seis anos analisados, com destaque de 7,88\% em 2011 e negativa apenas em 2010 com 7,11\%.

Observa-se que a estimativa das receitas tributárias prevista no orçamento demonstra a eficácia na elaboração do mesmo, tendo em vista que as receitas executadas superaram as receitas previstas, o que se torna relevante para obtenção de superávit orçamentário, pois as receitas tributárias representam $31 \%$ do montante das receitas totais, e $34 \%$ das receitas correntes arrecadas.

No conjunto das demais origens de receitas desta categoria econômica, em geral apresentam expressivas diferenças entre as receitas previstas e realizadas, e as diferenças em sua maioria são negativas, ou seja, frustrações de receita.

Desta forma, destaca-se nas Receitas de Contribuições o ano de 2015 que apresenta percentual de frustração de 33,81\%; nas Receitas Patrimoniais, os percentuais de 24,87\% em 2013 e 20,26\% em 2015; nas Receitas de Serviços o ano de 2011 com 29,85\% e em 2013 com 47,43\%. Em relação às Receitas de Transferências Correntes observa-se que em todos os anos houve 
arrecadação a menor do que o previsto, tendo como média $9,20 \%$.

Por outro lado, os percentuais positivos da execução das Receitas Correntes, aparecem nas Receitas de Contribuições, Outras Receitas Correntes, mas com destaque para as Receitas Patrimoniais, pois em 2011 e 2012 as receitas realizadas superaram as receitas previstas em $67,20 \%$ e $42,55 \%$ respectivamente.

Em relação à execução das Receitas de Capital, nota-se que em todos os anos do período em estudo houve menor arrecadação em confronto ao que estava prevista, com percentuais de acima dos 50\%, representando um contínuo erro de previsão, com destaca para o ano de 2011 com 77,38\%.

Nas Receitas de Capital a origem de receita que apresenta maior discrepância de variação é Alienação de Bens, que em 2011 apresentou frustração de receita de $73,55 \%$ e em 2012 apresentou percentual de execução positivo de $30,63 \%$.

As demais origens de Receitas de Capital, as Operações de Crédito, Amortização de Empréstimos e Transferências de Capital apresentam percentuais elevados de frustrações de receitas, com destaque para esta última que obteve percentual acima dos $70 \%$, chegando em 2015 a 96,91\%.

Referindo-se a previsão e a arrecadação das receitas, no período analisado, percebe-se que a execução orçamentária das receitas não está ocorrendo de forma equilibrada em relação ao que foi estimado com o que foi executado, demonstrando assim uma necessidade de aprimoramento nos instrumentos de planejamento orçamentário do Estado do Tocantins, quanto à metodologia de cálculo e premissas utilizadas na elaboração da Lei Orçamentária Anual.

\section{CONCLUSÃO}

Este estudo buscou apresentar os aspectos qualitativos e quantitativos dos recursos públicos que no orçamento são representados pelas Receitas e Despesas Públicas, mais especificamente a composição orçamentária do Estado do Tocantins, quanto às receitas arrecadadas e às despesas executadas no período de 2010 a 2015.

Contudo, na execução das despesas orçamentárias como um todo, percebeu-se que diferentemente das receitas os gastos vêm ocorrendo de forma equilibrada e programada, tendo em vista que em nenhum dos anos as despesas pagas foram superiores ao que estava previsto.

No que diz respeito à composição do total da receita disponível do estado, a maior parte é gerada pelas transferências correntes e não pela arrecadação de recursos próprios. Entretanto isto vem se alterando com o aumento na arrecadação, principalmente do ICMS e IPVA, em detrimento da queda das transferências.

Deixa-se como sugestão para as próximas pesquisas, analisar que componentes das receitas e das despesas públicas influenciam no crescimento e desenvolvimento econômico do estado do Tocantins.

\section{REFERÊNCIAS}

BRASIL, Lei Federal $\mathbf{n}^{\circ} 101$ de 04 de maio de 2000. Disponível em: <http://www.planalto.gov.br/ccivil_03/leis/LCP/Lcp1 01.htm>. Acesso em: 06 jul 2016.

BRASIL, Lei Federal $\mathbf{n}^{\circ} \mathbf{4 . 3 2 0}$ de 17 de março de 1964. Disponível em <http://www.planalto.gov.br/CCIVIL/Leis/L4320.ht m>. Acesso em: 21 maio 2016.

BRASIL. Constituição (1988). Constituição da República Federativa do Brasil. Brasília, DF: Senado Federal: Centro Gráfico, 1988. 292 p.

BRASIL. Controladoria-Geral da União. Transparência nos Estados e Municípios. Disponível em <http://br.transparencia.gov.br/tem/>. Acesso em: 03 jun. 2016.

BRASIL. MINISTÉRIO DA FAZENDA. Política Fiscal. Disponível em: <http://www.tesouro.fazenda.gov.br/pt_PT/sobrepolitica-fiscal>. Acesso em: 06 jul 2016. 
BRASIL. MINISTÉRIO DE PLANEJAMENTO ORÇAMENTO E GESTÃO. Elaboração e execução do orçamento. Disponível em: <http://www.planejamento.gov.br/servicos/faq/orcam ento-da-uniao/elaboracao-e-execucao-doorcamento>. Acesso em 31 maio 2016.

BRASIL. MINISTÉRIO DE PLANEJAMENTO ORÇAMENTO E GESTÃO. Orçamento Federal. Disponível em:

<http://www.orcamentofederal.gov.br/glossario>.

Acesso em: 31 maio 2016.

BRASIL. Portaria Conjunta STN/SOF no 03 de 14 de outubro de 2008 ( $11^{a}$ Edição do Manual da Despesa Nacional). Disponível em:< http://www3.tesouro.gov.br/contabilidade_governam ental/download/Manual_Despesa_Nacional_3010200 8_MTCASP_pdf >. Acesso em: 11 jun. 2016.

BRASIL. Portaria Conjunta STN/SOF no 03 de 14 de outubro de 2008 ( $1^{a}$ Edição do Manual da Receita Nacional). Disponível em:< ://www3.tesouro.gov.br/contabilidade_governamental /download/Manual_Receita_Nacional_30102008_M TCASP.pdf >. Acesso em: 10 jun. 2016.

GIAMBIAGI, Fábio; ALÉM, Ana Cláudia. Finanças públicas: Teoria e prática no Brasil. São Paulo: Campus, 2008.

IBGE - Instituto Brasileiro de Geografia e Estatística. Disponível em: 〈http://www.ibge.gov.br/estadosat> Acesso em: 13 mar. 2016.

IBGE - Instituto Brasileiro de Geografia e Estatística. Projeção Populacional. Disponível em: < http://www.ibge.gov.br/apps/populacao/projecao/> Acesso em: 20 jun. 2016.
KOHAMA, Heilio. Balanços Públicos: Teoria e Prática. 2. ed. São Paulo: Atlas, 2011.

PALUDO, Augustinho. Orçamento público, administração financeira e orçamentária e lei de responsabilidade fiscal. 2. ed. Rio de Janeiro: Elsevier, 2011.

PINDYCK, R. S., RUBINFELD, D. L. Microeconomia. 7. ed. São Paulo: Pearson, 2010.

REZENDE, Fernando. Finanças Públicas. 2. ed. São Paulo: Atlas, 2001.

RIANI, Flávio. Economia do setor público: uma abordagem introdutória. 5. ed. Rio de Janeiro: LTC, 2009.

TOCANTINS, Representação. Disponível em: <http://representacao.to.gov.br/conheca-o-tocantins>. Acesso em: 20 jun. 2016.

TOCANTINS. Perfil Sócio Econômico. Disponível em: $\quad<$ http://portal.to.gov.br/invista-notocantins/perfil-socioeconomico $>$. Acesso em 20 jun. 2016.

TOCANTINS. Portal da transparência. Despesas. Disponível em: <http://transparencia.to.gov.br/despesas/Acesso em 03 de abr. de 2016.

TOCANTINS. Portal da transparência. Receitas. Disponível em: <http://transparencia.to.gov.br/receitas/> Acesso em 02 de abr. de 2016.

TOCANTINS. Secretaria da Fazenda. Produto Interno Bruto. Disponível em: <http://www.sefaz.to.gov.br/> Acesso em: 01 jul. 2016. 